\title{
Márgenes de la ley: epifenómenos de violencia biopolítica*
}

\author{
Pablo Pérez Navarro**
}

\section{Resumen}

El objetivo de este artículo es desarrollar un marco teórico desde el cual repensar las formas de violencia estatal implícitas en un conjunto interrelacionado de prácticas institucionales, administrativas y judiciales en los ámbitos de las políticas genéricas, de la sexualidad y de la diversidad relacional. A través del caso de la España post-"matrimonio igualitario", se muestra cómo la introducción del concepto de "orden público" en los sistemas judiciales modernos ha jugado, y continúa haciéndolo hoy en día, un importante papel en la administración biopolítica de poblaciones.

Palabras clave: $\quad$ Orden Público, Biopolítica, Violencia Administrativa, Reproducción, Monogamia, España.

\footnotetext{
" Recebido em 23 de setembro de 2016, aceito em 17 de janeiro de 2018. Este articulo ha ido desarrollado en el marco del proyecto "INTIMATE - Citizenship, Care and Choice: The Micropolitics of Intimacy in Southern Europe" [338452], financiado por el European Research Council.

** Pesquisador no Centro de Estudos Sociais, Universidade de Coimbra, Coimbra, Portugal.ppabloperez@ces.uc.pt
} 
Margins of The Law: Epiphenomena of Biopolitical Violence

\begin{abstract}
This article's aim is offer a theoretical frame for rethinking forms of state violence implicit in an interrelated set of institutional, administrative and judicial practices dealing with the politics of gender, sexuality and relational diversity. Drawing on the case of post-"equal marriage" Spain, it shows the extent to which the introduction of the concept of "public order" in modern judicial systems has played, and still does, a major role in the biopolitical administration of populations
\end{abstract}

Keywords: Public Order, Biopolitics, Administrative Violence, Reproduction, Monogamy, Spain. 
Que el derecho sea deconstruible no es una desgracia. Podemos incluso ver ahí la oportunidad política de todo progreso

histórico

(Jacques Derrida).

\section{Introducción}

Quien, inquieta por las incontables referencias al "orden público" en las sentencias judiciales relativas a la vida administrativa del género, a la diversidad relacional o a los derechos reproductivos en el contexto del Estado español, se aproximara a la literatura jurídica en busca de esclarecer el significado de tan ubicuo y polivalente concepto, se enfrentaría sin duda a una frustrante sorpresa. Pues si algo llama la atención a primera vista en los ensayos de las juristas sobre el mismo, es la multitud de referencias a la extrema dificultad de acotar el significado de este "arquetipo limitador de los derechos fundamentales en general" (Martínez, 2014:769). Así, en su amplio ensayo sobre el orden público, Ángel Acedo (1997:326) observa que "la doctrina civilista española ha intentado en algunas ocasiones, muy pocas por cierto, y con escaso éxito casi siempre, aproximarse a una noción precisa de orden público" y que "los civilistas se han visto y se ven forzados a la tarea ingrata, difícil, quizá imposible, de explicar y definir lo sea el orden público" (de Castro y Bravo, 1982, apud Acedo, 1997:325). Otros consideran que se trataría, "de un concepto subjetivo, en blanco" (Montalvo Abiol, 2010:198), entre otras cosas porque "el ordenamiento jurídico no nos obsequia con definición alguna del mismo" (201). Situación por la que, concluyen aún otros, se trataría de "un término fragmentado y potencialmente peligroso como instrumento de limitación institucional de los derechos fundamentales de los ciudadanos" (Ortega, 2003:16, cursivas mías).

Alcanza el consenso, en cualquier caso, a situar su origen en el derecho romano, vinculado a un cierto ius publicum que sería "imposible de derogar mediante la voluntad privada" (AcedoPenco, 1997:329; Muñoz, 2007:15). Su ingreso en el derecho 
moderno, tras un largo periplo por el derecho medieval y del antiguo régimen (Noriega, 2007:8) habría tenido lugar con su inclusión en el sexto artículo del código civil napoleónico de 1804 (Ángel, 1997:332; Echandia, 1946:251; Muñoz, 2007:16; Noriega, 2007:10), por el que se establecía que "no se pueden derogar por convenios particulares las leyes que interesan al orden público y las buenas costumbres". ${ }^{1}$ Dada la influencia del code, este límite del principio liberal de no injerencia del estado en las libertades individuales pasó a convertirse en un ingrediente clave de la mayor parte de los códigos civiles europeos y latinoamericanos (Noriega, 2007:10); además de estar muy presente (aunque por otros caminos) en el derecho anglosajón, donde fundamenta la criminalización de los tradicionalmente llamados crímenes "sin víctimas", esto es, contra el orden público. ${ }^{2}$

Común resulta además la distinción entre algo así como un sentido "vulgar" (Acedo-Penco, 1997:338) del orden público y otro técnico o propiamente jurídico. El primero, a veces referido como "orden público de policía" (Echandia, 1946:252) u "orden material" (Ortega, 2003:19), estaría directamente asociado a la ausencia de disturbios en el espacio público. De él se ocuparía en la actualidad la Ley Orgánica de protección de la seguridad ciudadana (Ascensión, 2008:6), popularmente conocida como ley mordaza. ${ }^{3} \mathrm{El}$ segundo sentido es el que principalmente nos ocupa y se refiere,

1 "On ne peut déroger, par des conventions particulières, aux dispositions qui intéressent l'ordre public et les bonnes mœurs, Code civil des Français (1804), Art. 6.

${ }^{2}$ En cuya tipificación destacan las llamadas Public Order Acts del Reino Unido y otros países.

3 Diseñada ad hoc para criminalizar formas emergentes de la protesta social tras la irrupción del Movimiento 15-M. Según un editorial del New York Times, se trataría de una vuelta a los "tiempos oscuros del franquismo" ("Spain's Ominous Gag Law", 22-4-2015, http://www.nytimes.com/2015/04/23/opinion/ spainsominous-gaq-law.html? $\mathrm{r}=0$ ). Esta asociación resulta especialmente acertada si tenemos en cuenta que vino a endurecer otra ley de seguridad ciudadana (la llamada ley Corcuera) que sucedió, por su parte, a la Ley de Orden Público franquista (Sol, 2012). 
por su parte, al mantenimiento del orden en el difícilmente delimitable ámbito de los principios y valores fundamentales que sostienen el conjunto del ordenamiento jurídico (Ortega, 2003:23). A este se refiere el Tribunal Constitucional cuando dictamina que el "respeto a los derechos fundamentales y libertades públicas garantizados por la Constitución es un componente esencial del orden público" ", así como el Tribunal Supremo cuando explica, por su parte, que el orden público está "constituido por los principios jurídicos, públicos y privados, políticos, morales y económicos, que son absolutamente obligatorios para la conservación del orden social en un pueblo y en una época determinada". ${ }^{5}$

Uno de los más dilatados debates al respecto de este sentido jurídico consiste en determinar si coincide con, o más bien excede a, el conjunto de normas efectivamente escritas en la legislación. En el ya citado tratado Ángel Acedo (1997:328) propone, superando en cierto modo el debate, entender al orden público como "instrumento de cierre del ordenamiento en manos de los jueces". Interesante descripción que sitúa al orden público en una suerte de espacio limítrofe, entre la legislación y aquello que, posibilitando su "cierre", la excede. El concepto haría así suya la esquiva lógica del supplement derrideano, introduciéndose en la legislación como aquel tipo de "excedente" o, incluso, de "organismo parasitario" (Derrida, 1971:225) capaz de "enriquecer otra plenitud" sin producir "ningún relieve" (Derrida, 1971:185). La indecidibilidad ontológica (¿es el Orden Público, en definitiva, interior o exterior al ordenamiento?) a la que apunta tal posición tendría la ventaja, al menos, de explicar la intensidad del debate sobre si el orden público consiste o no en "ley y nada más que ley" o por qué los jueces, en cada uno de sus usos (o recitaciones performativas) del concepto, estarían ejerciendo algo así como

\footnotetext{
4 STC 19/1985, de 13 de febrero.

${ }^{5}$ STS de 5 de febrero de 2002, cursivas mías.
} 
una "función cuasi-legislativa" (Aguilar Navarro, 1953, apud Ángel, 1997:348).

En adelante, para diferenciarlo del anterior, nos referiremos a este sentido ${ }^{6}$ (meta)jurídico como Orden Público ${ }^{\odot}$. Su alcance se extiende por la casi totalidad de las ramas del derecho, desde el civil al constitucional, pasando por el laboral, el procesal o el administrativo (Ortega, 2003:16-22). El derecho familiar ${ }^{7}$ no es una excepción. Al contrario, las alusiones a este sentido del orden en las sentencias relacionadas con este ámbito tienen una bien consolidada historia. Las atribuciones del pater familias, por ejemplo, se imponían en la España de Franco sobre la base de que "si en un contrato celebrado entre cónyuges se dispensa a la mujer de la potestad marital, el acto es nulo absolutamente por ir contra el orden [público] familiar" (Echandia, 1946:258). Ya avanzada la transición se constataba que "las normas sobre la competencia y forma de autorización del matrimonio son de orden público y quedan obviamente sustraídas a la autonomía de la voluntad"8; mientras que, en la actualidad, los juristas suelen coincidir en que puede hablarse con propiedad de un "orden público familiar" (Acedo, 1997:363; García-Presas, 2010:241).

Cabe preguntarse, por tanto, por cuál es la forma que adopta el Orden Público ${ }^{\circ}$ en el ámbito familiar, es decir, a qué formas de parentesco y filiación alcanza el reconocimiento estatal y en qué exclusiones constitutivas descansa ese reconocimiento. En otros términos, y por señalar tan sólo algunas declinaciones posibles de esa pregunta y a cuyas posibles respuestas pretende apuntar este artículo, así sea con un carácter preliminar y

6 El uso de la marca "C)" o "copia registrada" sirve aquí para indicar su pertenencia, en tanto que copia, a una cadena histórica de iteraciones en instancias judiciales, tanto como la pretensión de cada una de esas citas de consolidar los límites de una cierta identidad que es, como veremos, cultural y legislativa a un tiempo.

7 Entendido como "conjunto de normas jurídicas de derecho privado que regulan la familia en todos sus aspectos" (García-Presas, 2010:240).

824 de septiembre de 1987 (cfr. Acedo, 1997: 388). 
tentativo, ¿continúa el Orden Público ${ }^{\odot}$ reafirmando la primacía de la heterosexualidad o supuso el matrimonio igualitario, por el contrario, la superación plena de esta? ¿Hasta qué punto transformó la extensión del derecho a la adopción las estructuras heterosexuales de la filiación? ¿Qué límites establecen en su nombre los juzgados a la diversidad relacional y qué lugar ocupa en ellos la monogamia? ¿En qué medida se fundamenta este orden familiar en la concepción binaria del género? ¿Cómo interacciona, en fin, el Orden Público ${ }^{\odot}$ familiar con la construcción de identidades culturales y nacionales en sentido amplio?

\section{Orden público ${ }^{\odot}$ y heterosexualidad reproductiva}

Puede afirmarse con bastante tranquilidad que, pese a la exclusión de homosexuales y transexuales de la Ley de Peligrosidad y Rehabilitación Social (sucesora de la Ley de Vagos y Maleantes) en $1979^{9}$ (Trujillo, 2016:63), el Orden Público ${ }^{\odot}$ español continuó siendo estrictamente heterosexual hasta finales del siglo $\mathrm{XX}$. Momento en que, leyes autonómicas de parejas de hecho mediante (Pichardo-Galán, 2009:144), comenzó el proceso de desheterosexualización que se consumó con la promulgación de la ley estatal del matrimonio igualitario, adopción incluida, en el año 2005. Tal sería, al menos, la interpretación dominante desde el punto de vista de una cierta fetichización del matrimonio como símbolo de la igualdad formal que resulta, por lo demás, bastante ubicua (Platero-Méndez, 2007:93). Sin embargo, lo cierto es que basta una mirada a la regulación actual de las relaciones de filiación para poner en evidencia que incluso el desplazamiento meramente "formal" de la norma heterosexual está lejos de haber concluido. Muy al contrario, la flexibilización de las regulaciones del parentesco ha servido más bien para dejar al descubierto la biologizante infraestructura heterosexual del Orden Público ${ }^{\odot}$ familiar.

9 Si bien el más indirectamente relacionado delito de "escándalo público" no fue eliminado del código penal hasta 1988. 
Esta base heteronormativa de la filiación resulta evidente en relación con la inscripción de la llamada "filiación natural". En otras palabras, aquella que se establece de forma directa tras el nacimiento, sin mediación de procesos de adopción (HernándezRodríguez, 2014:160). Efectivamente, para comenzar, la ley de reproducción asistida vigente ${ }^{10}$ consagra la heterosexualidad como filiación por defecto con cada una de sus referencias a la figura del "marido" establecimiento la filiación en parejas lesbianas. Notoria ausencia que, si bien fue total en el momento de su promulgación pronto pasaría, en una corrección posterior ${ }^{12}$, a considerar el muy específico caso en que ambas madres se encuentren casadas entre sí (Díaz-Martínez, 2007:78; Trujillo, 2016:65). En consecuencia, la inscripción de la doble maternidad de nacimiento se permite en la práctica sólo cuando hay casamiento. Condición que, al no tener equivalente alguno en el abierto campo de la filiación heterosexual, resulta insólita en un cualquier supuesto escenario de "igualdad formal". A menos, claro está, que entendamos que esta no se estableció entre tipos de relaciones sino más bien entre matrimonios del mismo y de distinto sexo.

El caso de la filiación de nacimiento por parte de dos progenitores de sexo legal masculino no es menos llamativo. De hecho, la decisión sobre su legitimidad se encuentra en manos del Tribunal Constitucional, tras una batalla judicial que se va aproximando a la década de antigüedad y que, de mantener el actual rumbo, podría resolverse en el Tribunal Europeo de Derechos Humanos (TEDH). Todo ello como resultado de que la posibilidad de establecer una filiación de nacimiento sin figuras maternas es declarada ilegal en la ya citada ley de reproducción

\footnotetext{
${ }^{10}$ Ley 14/2006, actualizada por última vez en julio de 2015.

${ }^{11}$ Menciones del tipo: "Si la mujer estuviera casada, se precisará, además, el consentimiento de su marido..." (Art. 6) o "Ni la mujer progenitora ni el marido, cuando hayan prestado su consentimiento formal" (Art. 8).

${ }^{12} \mathrm{~A}$ través de la Ley $3 / 2007$.
} 
asistida, en la que se establece que los contratos de gestación subrogada no tienen efecto legal en el Estado español. ${ }^{13}$

En consecuencia, un número indeterminado ${ }^{14}$ de parejas subrogan anualmente la gestación en terceros países (Caravaca \& González, 2015:49; Hernández-Rodríguez, 2014:149). El actual conflicto se originó, en concreto, cuando un consulado español se negó a trasladar, al registro español, una doble paternidad masculina previamente inscrita en los Estados Unidos. Momento a partir del cual la relación de filiación entre estos padres (españoles) y los menores (estadounidenses) se encontró, junto a la de muchas otras parejas homoparentales, en un hostil limbo jurídico (BlancoMorales Limones, 2015:13). Desde entonces, si bien la inscripción de la filiación se ha ido facilitando tras sendas instrucciones de la Dirección General de Registros y Notariado (DGRN) y tres sentencias relacionadas del TEDH contra Francia e Italia (Caravaca \& González, 2015:54-55), el llamado "caso cero" prosigue su curso. Las sentencias dictadas hasta la fecha esgrimen múltiples argumentos, entre los que destacan por derecho propio el de que la filiación que se pretendía inscribir "ni es ni puede serlo a efectos materiales, pues biológicamente resulta imposible"15 y el de que, como argumenta el Tribunal Supremo, la inscripción atenta contra el "orden público internacional". ${ }^{16}$

${ }^{13}$ Ley 14/2006, Art. 10.

${ }^{14}$ Según algunos cálculos de agencias especializadas podría situarse en torno a las 1000 "parejas" por año. El País, "Las familias españolas buscan vientres de alquiler 'baratos", 1 de mayo 2014, http://sociedad.elpais.com/sociedad/2014/05/01/actualidad/1398974404_290772 .html.

15 Juzgado de Primera Instancia N ${ }^{\circ} .15$ de Valencia, 15 Sep. 2010. Cursivas mías. ${ }^{16}$ STS 6 febrero 2014. En general, se entiende por "orden público internacional" aquella dimensión del orden público propia del Derecho Internacional Privado que impide el reconocimiento de los efectos de cualquier ley extranjera (en este caso, la que permitió la inscripción de la filiación de nacimiento) cuando esta perturba en demasía lo que aquí hemos venido llamando Orden Público (Monreal, 1976:122-123). 
Así las cosas, puede afirmarse que el Orden Público ${ }^{\circ}$ español internacionaliza, por una parte, el recurso a la gestación subrogada, de forma similar a lo que no hace tanto hiciera con el aborto, esto es, limitando su acceso en función de los costes que la mediación de kilómetros (e intermediarios) supone. A la vez que, por la otra, hostiga muy específicamente ${ }^{17}$ el tipo de filiación que considera "biológicamente imposible", pese a que son más bien las sentencias judiciales, antes que la biología, las que impiden su reconocimiento. ${ }^{18}$ En consonancia, claro está, con una ley de reproducción asistida que perpetúa ese "heterosexismo de estado" para el que la "unión sexopolítica entre un hombre y una mujer son las condiciones necesarias e inmutables para la reproducción" (Preciado, 2014); a la par que se aferra a un marcado biologicismo que demuestra, en fin, que la pretendida superación del "continuo coito/alianza/filiación" (Pichardo-Galán; Stéfano-Barbero; MartínChiappe, 2015:189) está lejos de haber sido consumada mediante la mera extensión del derecho a la adopción. Antes bien, la fragmentación de ese continuo ha servido más bien para dejar al descubierto un estrato más profundo de la filiación heterocentrada, a saber, un continuo "parto/matrimonio/filiación" que domestica las posibilidades de la doble maternidad lesbiana a la par que pretende cancelar las de una filiación de nacimiento exclusivamente masculina.

En parte, al menos, porque la filiación de nacimiento sin figura materna representa una ruptura con el aún vigente pilar de

\footnotetext{
${ }^{17} \mathrm{Al}$ parecer, las subrogaciones heterosexuales (entre el 70 y el 80 por ciento del total, según algunas estimaciones; "Papá, mamá y la tía Samantha" 2015) resultan invisibles para los funcionarios y juzgados españoles, incluso cuando, como explican desde Son Nuestros Hijos, las fechas de nacimiento y las de entrada de sus progenitores en el país de destino ponen frecuentemente en evidencia la mediación de la subrogación (http://sonnuestroshijos.blogspot.pt/p/nuestros-hijos-son-espanoles.html).

${ }^{18}$ Pero que alcanza un espectro de cuestiones administrativas relacionadas, como las negativas al disfrute de la llamada baja por "maternidad" en ausencia de una figura materna.
} 
la filiación en el derecho romano, el mater sempre certa est. Tomando en consideración el desafío a la concepción tradicional de la reproducción que esta ruptura supone (ruptura que lleva a entender que en un proceso de gestación subrogada existirá una presencia materna en función de que exista o no una madre de intención) resulta fácil de entender que otras formas de reproducción que no requieren de figuras maternas, como las de las gestaciones trans masculinas, se asocien con la gestación subrogada incluso en la percepción que los padres gestantes tienen de sí mismos. Así por ejemplo, Thomas Beatie, el erróneamente identificado por los medios como "primer hombre gestante" (Halberstam, 2012:65), afirmaba justamente verse a sí mismo "como un vientre de alquiler, aunque mi identidad de género como varón es constante" (Green \& Friedman, 2015:88). Se explica también de la misma forma que la gestación trans masculina sea igualmente objeto de discursos que tratan de relegarla a espacios de simple abyección social (Halberstam, 2012:67), procedentes incluso del ámbito de las propias comunidades trans; además de la obvia exclusión legislativa de las gestaciones masculinas manifiesta, en el caso del Estado español, en la omnipresencia de la trans-excluyente figura de la "mujer receptora" (de la inseminación) en la ley de reproducción asistida. Exclusión social y jurídica de la posibilidad de una gestación sin madre, pues, que emparenta la gestación trans masculina con la gestación subrogada, vistas las campañas de rechazo que ciertos sectores feministas, cuando no del activismo LGTB, han llegado a manifestar en los últimos años, tratando de sofocar con bastante virulencia la apertura de un debate en torno a la posible regulación de la misma en España. ${ }^{19}$

Al fin y al cabo, en lo que a su capacidad para poner en crisis el régimen cis-heterosexual se refiere, incluso la más

\footnotetext{
${ }^{19}$ Entre las que destaca la plataforma No somos vasijas, cuyo manifiesto fundacional se refiere a la decisión de gestar para otras personas como "violencia obstétrica exrema" [http://nosomosvasijas.eu/].
} 
asimilacionista de las lecturas que de las gestaciones sin madre pueda hacerse, a partir de la lectura de No Future (necesariamente precipitada en mi opinión, al menos en el sentido de que Lee Edelman se detiene a clarificar que su crítica a la figura del niño usada por esa forma de la heteronormatividad que bautiza como futurismo reproductivo, no debe confundirse con ningún niño real o "histórico" ni, por ende, con ningún proyecto de reproducción concreto; Edelman, 2004:11), de las hipermediáticas fotos de Thomas Beatie o de la publicidad de las agencias de subrogación, antes o después tiene que enfrentar el antisocial fantasma de la filiación de nacimiento marica que contundentemente invocaran Almodóvar y Fabio McNamara en Voy a ser mamá. ${ }^{20}$

\section{Políticas genéricas del nombre propio}

Por supuesto, el alcance disciplinario del Orden Público ${ }^{\circ}$ sobre la diversidad genérica, deseante y relacional está lejos de limitarse a la consolidación del biopolítico nexo entre "madres" y "gestantes". E incluso esta requiere, como toda la inercia heterosexualizante del dicho orden en su conjunto, de un gesto fundante que permita articular los mimbres legales de esa articulación normativa entre sexos, géneros y deseos que Butler denominó "matriz heterosexual" (Butler, 2007:36).

El hecho de que en el Estado español existan dos, y sólo dos, posibilidades para la obligatoria inscripción registral del sexo, que su alteración esté restringida a la mayoría de edad, a unos

\footnotetext{
${ }^{20}$ Cuya segunda estrofa reza así:

"Sí voy a ser mamá

No quiero abortar

Rechazo la espiral

Tiene derecho a vivir

Le llamaré Lucifer, le enseñaré a criticar

Le enseñaré a vivir de la prostitución

Le enseñaré a matar

Oh sí, voy a ser mamá."
} 
rígidamente estipulados períodos de hormonación previa (Morelo, 2007:151), a la supervisión de la autoridad médico-psiquiátrica en unidades específicas $y$, en suma, a criterios heterónomos y procesos patologizantes, permite intuir la intensidad de la violencia "de género" (Coll-Planas, 2010:55) que el marco binario descarga, en especial, sobre todo el abanico de las identidades trans. Entre las poliédricas dimensiones del así estatalizado "orden de género" (Lombardo, 2003, apud Platero-Méndez, 2007:4) destaca, dados sus efectos sobre el variado conjunto de prácticas institucionales y burocráticas binarias que Dean Spade (2015:168) denomina "violencia administrativa", las marcas de género de los documentos de identidad. Marcas, en plural, dado que no se limitan a la obvia referencia al sexo legal que Monique Wittig comparara en "La categoría de sexo" con la mención de la raza en los documentos de identidad durante el apogeo del racismo de estado en los Estados Unidos; 1992:29), sino que incluyen, además, ese otro signo lingüístico mediante el cual el binarismo de género tiende a invadir, literalmente, nuestra vida cotidiana desde nuestra más tierna infancia: el llamado nombre propio.

Ciertamente, entre las restricciones impuestas por la ley que regula actualmente la inscripción del nacimiento, de la filiación, del nombre y de sus posibles cambios se encuentra la de que el nombre no debe hacer "confusa la identificación". ${ }^{21}$ En la práctica administrativa y judicial, esta confusión incluye sin duda la genérica, como ya se insinúa en aquel primerísimo artículo de la ley de identidad de género que recuerda que el cambio de sexo debe acompañarse con el de nombre, a fin de que estos no resulten "discordantes". ${ }^{22}$ De ahí que sea bastante común referirse a la transición legal de sexo con fórmulas mixtas del tipo "cambio del registro legal del nombre/sexo" (Suess, 2010:38) y que pueda afirmarse que, al menos por lo que al establecimiento del sexo legal se refiere, la mención registral del nombre propio tiene un

\footnotetext{
${ }^{21}$ Ley 20/2011, de 21 de julio, del Registro Civil, Art. 51.

${ }^{22}$ Ley 3/2007, Art. 1.
} 
efecto equivalente al de la mención del sexo. Situación que explica que, hoy por hoy, el cambio de nombre en menores trans, incluso sin cambio de la mención registral de $\operatorname{sexo}^{23}$, se encuentre totalmente judicalizado (Platero, 2014:173), en claro contraste con la rutinaria sencillez del trámite de cambio de nombre "intragénero", o que los autos que lo autorizan recurran aún hoy a justificarse con diagnósticos de "disforia de género" ${ }^{24}$, como si de un cambio de sexo legal se tratara.

Así pues, dada la importancia del binarismo de género como fundamento de las presunciones de heterosexualidad que aún habitan nuestro sistema legislativo, no resulta sorprendente que el establecimiento del nombre ( $\mathrm{y}$ apellidos, pese a que estos se encuentren bastante más emancipados del binarismo genérico) sea todavía un asunto de Orden Público ${ }^{\odot}$ de primer orden. $\mathrm{O}$, incluso, "donde más continuamente se trata esta materia [el orden público] en los registros civiles" (Acedo-Penco, 1997:388). Y es que ese nombre tan mal llamado "propio", marca lingüística con la que tan íntimamente tendemos a (des)identificarnos, no es un simple performativo de género entre otros, como bien saben quienes batallan por la autodeterminación de su sexo/nombre legal. A diferencia del de muchas de las "invenciones fabricadas y preservadas mediante signos corpóreos y otros medios discursivos" (Butler, 2007:266), la repetición del nombre sexuado, desde el documento que registra la filiación hasta el de defunción (pensemos en la cantidad de lápidas que no respetan la identidad de género de los cuerpos bajo ellas enterrados) conlleva una inscripción de la ley binaria del género en nuestra carne material y administrativa digna de la máquina de la colonia penitenciaria de Kafka.

\footnotetext{
${ }^{23}$ El Mundo, "El Supremo ve inconstitucional que los menores transexuales no puedan inscribir el cambio de sexo" [http://www.elmundo.es/sociedad/2016/03/17/56ea93c0ca4741601d8b45fb.htm] ${ }^{24}$ El Mundo, "Autorizan a una niña de cuatro años cambiar de nombre por motivos de transexualidad en Gipuzkoa", 2-2-2016 [http://www.elmundo.es/paisvasco/2016/02/02/56b0b133ca474161538b45ab.html].
} 
Efectivamente, el lugar que ocupa el nombre propio en relación al ejercicio de la violencia representa un singular cruce de las fuentes de la violencia performativa implicada en el carácter heterónomo de la asignación del nombre propio. Por un lado, la ya referida violencia administrativa, esto es, la inscripción en un sistema burocrático del género en relación a cuyos binarismos se determinará el acceso a determinados servicios, la apertura de determinadas posibilidades de reasignación genérica o el lugar a ocupar en ella, distribución de precariedades en un mercado laboral marcado por la transfobia. Violencia esta que se sostiene, pues, en la articulación del poder performativo del estado en los procesos registrales del nacimiento y en las resoluciones que conceden o deniegan el derecho al cambio de nombre. Conviene señalar además, por el otro, para comprender mejor el alcance de esta violencia administrativa, el hecho de que se trata siempre ya de una violencia de segundo orden, pues descansa sobre la violencia que la imposición originaria del nombre propio, en sentido meramente social o extrajurídico representa. Esta imposición no estatal del nombre descansa, ahora en términos del Derrida de De la gramatología, sobre el obliteramiento de la singular unicidad del sujeto en manos del mal llamado nombre "propio" (Derrida, 1971:145). En otros términos, la asignación del nombre consiste en la imposición de una marca que no es ya única ni mucho menos "propia" a través de la que se produce, en parte al menos, el ingreso del sujeto en un determinado contexto lingüístico. La violencia originaria que este proceso supone vendría dada, según la lectura del nombre propio que propone Derrida por su forma de adjudicar "designación de pertenencia y clasificación lingüístico-social" (Derrida, 1971:146), esto es, por el poder "clasificatorio" de un nombre que inscribe al sujeto en diversos sistemas de pertenencia grupal.

Cierto es que, en su discusión del tratamiento del nombre propio por parte de Levi-Strauss, Derrida no nombra al binarismo de género entre estas clasificaciones grupales, naturalizando así hasta cierto punto con este olvido, en el contexto de esta reflexión sobre el poder clasificatorio del nombre propio, la relación entre el 
nombre y la diferencia sexual. Dejando esta omisión al margen, sin embargo, lo que el análisis de Derrida facilita comprender es que, a través de las políticas administrativas del nombre propio el estado asume entre sus competencias nada menos que el ejercicio y regulación de esta forma originaria de violencia lingüística, clasificatoria, en la que el binarismo de género ocupa un lugar central. Me gustaría señalar, para concluir esta reflexión, que esta asunción conlleva una coincidencia entre las prácticas administrativas del estado en torno al nombre y la producción de discurso de odio. Reflexionando justamente sobre algunas relaciones entre el estado y los discursos de odio en Lenguaje, poder e identidad, Judith Butler observaba cómo los procesos judiciales en torno al discurso del odio reproducen, en la forma del performativo estatal, la violencia lingüística cuyos efectos legales se tratan de dirimir en sede judicial. El argumento de Butler pasaba tanto por la necesidad de la minuciosa recitación de aquello que fue dicho (Butler, 1997:130), como por el propio poder performativo concedido al estado con el que este confirma el poder hiriente del discurso del odio (134). La contraintuitiva conclusión de la crítica de Butler rezaba por tanto que la "censura estatal produce discurso del odio" (Butler, 1997:134). Pues bien, de forma similar, las políticas del nombre propio, en cuya forma ideal deberían permitir la propia identificación en las antípodas de la lógica del insulto, en dirección a la autonomía asociada a una suerte de "tener" un nombre por oposición al ser llamado uno ${ }^{25}$ devienen ellas mismas, al convertir al propio nombre en una marca de género heterónomamente impuesta y administrada, en una variante del discurso del odio.

\section{Cisheteromonormatividad}

Así disciplinado, nombre y marca de género mediante, el binarismo queda listo para organizar el campo de las unidades

${ }^{25}$ Being called names es precisamente la traducción, al inglés, de "ser insultado". 
familiares y reproductivas. Siempre dentro, claro está, de un marco jurídico que añade, a la infraestructura heterosexual de la filiación, al menos otro ingrediente clave para la regulación del ámbito genérico, deseante y relacional. Uno que se mantiene en la actualidad en un estupendo estado de salud, a saber, ese ubicuo elemento cuyas implicaciones no sólo jurídicas, sino sociales y culturales en sentido amplio reúne Brigitte Vasallo bajo la denominación de "marco monógamo" (Vasallo, 2015).

Su relación con lo que venimos llamando Orden Público ${ }^{\odot}$ es, si cabe, aún más estrecha que la de la propia heterosexualidad o el binarismo sexogenérico. Al menos en el sentido de que, como componente de la institución matrimonial y sus derivados, la monogamia atraviesa los siglos, en ese entorno geopolítico que solemos denominar "occidente", apenas sin inmutarse. Presente ya en la regulación del matrimonio del derecho romano y posteriormente sublimada en el derecho canónico, ingresó en el derecho moderno, incólume, a comienzos del siglo XIX, en el ya citado código napoleónico (Caravaca \& González, 2005:21). Momento en que se estataliza, mediante la administración civil de la "unión entre varón y mujer", la bien avenida troika constituida por el binarismo de género, su jerarquizada complementariedad heterosexual $y$, organizando esta en unas fácilmente censables unidades reproductivas, la monogamia.

La coincidencia, en este texto inaugural del derecho moderno, de la introducción del Orden Público ${ }^{\circledR}$ como límite de las libertades individuales y el matrimonio civil representa un hito histórico en la evolución del control biopolítico de poblaciones a gran escala. Es más, dada la vida posterior de ambos fetiches jurídicos, y la de sus íntimas relaciones, puede argumentarse que esta sincronía elevó de hecho la citada tríada al estatuto de Orden Público $^{\oplus}$, convenientemente reunida en una única institución. Lo que así se secularizó no fue, en consecuencia, tanto el sacramento matrimonial como la potestad para la gestión del régimen 
cisheteromonormativo ${ }^{26}$, entendido este como el control estatal de la matriz heterosexual en aquellos entornos (temporales, espaciales o jurídicos) que privilegian la monogamia a la par que discriminan y ejercen diversas formas de violencia administrativa sobre otras estructuras relacionales, sean estas de origen religioso, laico o aconfesional.

Actualmente, los y las migrantes polígamas se encuentran, junto al bebé sin papeles de la subrogada y las infancias trans, entre los más evidentes exponentes de la violencia que este régimen despliega en el Estado español y otros muchos de su entorno sobre quienes viven en conflicto con cualquiera de sus tres ejes constitutivos. Los casos de las viudas de relaciones polígamas a las que se ha concedido el derecho a recibir sus correspondientes pensiones de viudedad, en virtud de la aplicación del denominado "orden público atenuado" (Calvo Caravaca \& Carrascosa-González, 2007:470; Campiglio, 2012:165; Lema-Tomé, 2003:17) son apenas el reverso amable de una excluyente praxis jurídica que comprende desde la denegación del derecho a la reagrupación familiar (Labaca-Zabala, 2009) hasta la de las solicitudes de nacionalidad.

En especial, en las sentencias referidas a este último caso, el repetido argumento de que la poligamia "repugna al orden público español" ${ }^{27}$ deviene sistemáticamente prueba de una supuesta "falta de integración en la sociedad española". ${ }^{28}$ Se produce con ello un sustancial cambio de registro entre el tipo de conflicto jurídico por el que habitualmente se apela a la cláusula de "orden público internacional" para no reconocer los efectos de

${ }^{26} \mathrm{El}$ término "cisheteromonormativo" resulta del injerto entre los de heteronormatividad (Warner, 1991) y mononormatividad (Pieper M. \& Bauer, 2005), al que añado el prefijo cis para destacar el binarismo de género sobre el que descansa tanto la complementariedad heterosexual (dimensión cualitativa) como la restricción monógama (dimensión cuantitativa).

${ }^{27}$ Ver por ejemplo las sentencias del Tribunal Supremo 6358/2002 y 4764/2009, o la de la Audiencia Nacional de 14 de marzo de 2013.

${ }^{28}$ Idem. 
leyes extranjeras incompatibles con la propia (Monreal, 1976:121) al del juicio de valor sobre supuestos grados de integración social. Así, más que a efectos jurídicos aceptables o no para la jurisprudencia (como las propias pensiones de viudedad) se convierte a individuos concretos en el muy corpóreo objeto de aplicación del Orden Público ${ }^{\circledR}$. Sustancial giro en virtud del cual el régimen cisheteromonormativo despliega su potencial para el ejercicio de la violencia estatal implícita en la amenaza o en la realidad efectiva de la deportación a la par que pone en evidencia alguna de sus ramificaciones en materia de políticas migratorias y, a través de estas, de sus intensas relaciones con el clasismo, la xenofobia, el racismo y la discriminación religiosa.

Este recurso implícito a una homogénea, monolítica y monógama concepción de la "sociedad española", dista mucho de ser, por lo demás, un complemento casual del recurso al Orden Público $^{\circ}$. Antes bien, es digno descendiente de una sus más propias líneas genealógicas. Según explica uno de sus exégetas más influyentes, M. Savigny, el Orden Público ${ }^{\odot}$ fue introducido en el derecho moderno nada menos que como garante de la comunión entre "los pueblos de occidente, asentada en el cristianismo y en el Derecho Romano" (Monreal, 1976:123; Savigny, 1851:35). Su función no sería por tanto otra que la de proteger, según otros eruditos de la doctrina francesa, "los principios comunes a las naciones civilizadas (...) expresión de la moral y la justicia objetivas" (Lerebours-pigeonniere \& Loussouarn, 1962:500; Monreal, 1976:124) de perturbadoras influencias extranjeras. Universalista y xenófoba genealogía, pues, que contribuye quizá a explicar el lugar que ocupa el matrimonio como peculiar alternativa a las políticas de asilo, como si de una suerte de versión moderna de la figura de la conversión religiosa se tratara, así como que medidas de corte claramente islamofóbico, como la reciente prohibición de usar el burkini en hasta una docena de municipios franceses, se hayan fundamentado legal y políticamente en una preocupación por el mantenimiento del "orden público". Resulta clarificador, en este sentido, el modo en que las recientes ordenanzas al respecto, cuya legitimidad ha sido al fin puesta en 
entredicho por el Consejo de Seguridad francés, hablan del "trouble à l'ordre public" (sentido material del orden público) de un modo que lo hace en la práctica indistinguible del sentido universalista y normativo del Orden Público propiamente dicho. Este aspecto resulta evidente en la arbitrariedad de unas ordenanzas que combinan la prohibición con apelaciones a las "buenas costumbres" pero también, sobre todo, en las explicaciones políticas que han venido a complementar su implementación. La teniente alcalde de Niza, sin ir más lejos, ha explicado que se trata de mantener "nuestro ideal de la relación social" y de luchar "contra el comunitarismo" 29 mientras que la presidenta del Frente Nacional, Marine Le Pen, considera que se trata de una cuestión "de orden público, ciertamente; pero más allá, se trata de la esencia de Francia" 30 , constatando así la vigencia contemporánea de la histórica asociación del orden público con el mantenimiento de cierto ideal xenófobo de la identidad nacional.

\section{Desorden púb(l)ico: a modo de conclusión}

Aun concediendo un valor relativo a la sugerencia de que "Estado y Orden Público han ido de la mano desde el principio de los tiempos" (Montalvo-Abiol, 2010:205), resulta evidente que estamos ante un importante mecanismo por lo que a la reproducción de las variantes nacionales de la filiación, del género y de la diversidad relacional se refiere. De ahí la importancia de su desestabilización para cualquier política que pretenda hacer suyo el impulso critico que abría este ensayo: "ha llegado el momento

\footnotetext{
${ }^{29}$ Huffington Post, 19-08-2016 "Avant Nice, les communes françaises qui ont interdit le burkini sur leurs plages" [http://www.huffingtonpost.fr/2016/08/19/burkini-plages-interdiction-nice_n_11604624.html].

30 20Minutos, 16-08-2016, "Una docena de municipios ya prohíben el burkini en Francia" [http://www.20minutos.es/noticia/2818216/0/mujeres-multa-cannesfrancia-burkini-playa/\#xtor=AD-15\&xts=467263].
} 
de pensar en queerizar el estado" (Duggan, 2009:1). Aunque si algo así como pensar en esta queerificación es, de hecho, posible, lo será tal vez sólo a condición de asaltar la dicotomía entre distintos sentidos del orden, es decir, aquella que nos permite distinguir entre la ausencia de disturbios en el espacio público y el Orden Público $^{\circ}$ en sentido (meta)jurídico. Puesto que, tal y como observa desde la filosofía del derecho Miguel Álvarez Ortega, en un ensayo en que aboga justamente por una reformulación unificada del concepto, "sostener que una catástrofe natural no perturba el orden material o la paz social y una revuelta callejera sí no deja de ser sorprendente. Si optamos en cambio por considerar la quiebra de los valores sociales en juego, la distinción puede resultar más diáfana" (Ortega, 2003:25; cursivas mías).

La conexión así apuntada entre perturbación de la "paz social" y "quiebra" de los "valores sociales en juego" dista de indicar una mera posibilidad de reformulación teórica de un abstracto concepto jurídico. Antes bien, la existencia de un estrecho vínculo entre ambos sentidos del orden bien podría ser la intuición básica de, entre otras formas de activismo callejero y combativo, la que conocemos como activismo queer. Recorrería en ese caso tanto los disturbios de Stonewall (avant la lettre) como la visita de Act-Up a la misa de St. Patrick, los tragafuegos de las Lesbian Avengers o los kiss-ins de Queer Nation. Estaría también muy presente en las campañas "El Ministerio de Sanidad tiene las manos manchadas de sangre" de la Radical Gai, en la sexualizada cartelería lesbiana de LSD, en los die-ins de la Transmaricabollo de Sol contra el apartheid sanitario y en la defensa de los espacios de cruising de Barcelona de Triangles Rosas. Formaría también parte del combativo LGTB bloc de la resistencia del Gezi Park, de todas las asambleas queer de los movimientos Occupy, de la convocatoria antiausteritaria de las Panteras Rosa durante el Rios para o Carmo y también, sin lugar a dudas, del reciente asalto de Lesbians and Gays Support the Migrants al centro de detención de inmigrantes de Yarl's Wood. Sin olvidar la defensa del cruising de Montjuic por los Triangles Rosas y cada uno de los bloques nomonógamos, asexuales, kinks y BDSM, y de sus improbables 
coaliciones, en las marchas del Orgullo Crítico de Madrid y Barcelona. Todas estas formas de activismo, vinculadas de uno $\mathrm{u}$ otro modo con la ocupación crítica del espacio público, explotan la intuición de esa conexión por la que, en ocasiones, el más anárquico y minoritario desorden púb(l)ico deviene conmoción política. Cierto es que los efectos de este tipo de resonancias son, por definición, inanticipables. Por eso suelen captar toda la atención de las fuerzas del Orden Público.

\section{Referencias bibliográficas}

ACEDO-PENCO, Á. El orden público actual como límite a la autonomía de la voluntad en la doctrina y la jurisprudencia. Anuario de La Facultad de Derecho, 14-15, 1997, pp.323-392.

ASCENSIÓN, E. Libertad de circulación y orden público en España. Revista Para El Análisis Del Derecho (2), 2008, pp.1-19.

BLANCO-MORALES LIMONES, P. Una filiación: tres modalidades de establecimiento. La tensión entre la ley, la biología y el afecto. Bitácora Millennium DIPr., $\quad 1, \quad 2015$ [http://www.millenniumdipr.com/ba-4-una-filiacion-tres-modalidadesde-establecimiento-la-tension-entre-la-ley-la-biologia-y-el-afecto accedido el 28-06-2016].

BUTLER, J. Lenguaje, poder e identidad. Madrid, Síntesis, 1997.

. El género en disputa. Barcelona, Paidós, 2007.

Calvo-CaravaCA, A.; CARRASCosA-GonzÁlez, J. Derecho internacional privado y matrimonios entre personas del mismo sexo. Revista de Instituciones Europeas, vol. $1, \quad 2005$, pp.758-824 [http://eprints.ucm.es/7864/ - accedido el 28-06-2016].

. Los matrimonios entre personas del mismo sexo en la Unión Europea. Revista Crítica de Derecho Inmobiliario, 700, 2007, pp.443475.

Gestación por sustitución y derecho internacional privado. Más allá del tribunal supremo y del tribunal europeo de derechos humanos. Cuadernos de Derecho Transnacional, 7, Octubre 2015, pp.45-113. 
CAMPIGLIO, C. Los conflictos normo-culturales en el ámbito familiar, 4, Octubre 2012, pp.5-21.

COll-Planas, G. La policía del género. In: Missé, M.; Coll-Planas, G. (ed.). El género desordenado. Críticas en torno a la patologización de la transexualidad Barcelona y Madrid, Egales, 2010, pp.55-67.

DERRIDA, J. De la gramatología. México D.F., Siglo XXI Editores, 1971.

DíAz-MARTínEZ, A. La doble maternidad legal derivada de la utilización de técnicas de reproducción humana asistida. Derecho Privado $Y$ Constitución, 21, 2007, pp.75-129 [http://revistas.cepc.es/getData.ashx?MAVqs $=\sim$ aWQ9MjU5MDQma WRIPTEwMzcmdXJsPTUxJm5hbWU9RENQMjEuMDAzLnBkZiZma WxIPTY5MjAxNTU2OTQzMTU0My5wZGYmdGFibGE9QXJ0aWN1 bG8mY29udGVudD1hcHBsaWNhdGlvbi9wZGY = - accedido el 2806-2016].

DugGan, L. Queering the State. Social Text, 39, 1994, pp.1-14.

ECHANDIA, H. D. Evolucion de la noción de orden publico. Revista de La Universidad Nacional (1944 - 1992), 6, 1946, pp.251-262.

Edelman, L. No Future. Queer Theory and the Death Drive. Durham and London, Duke University Press, 2004.

GARCíA-PRESAS, I. El derecho de familia en España desde las últimas reformas del código civil. In: Actas del I Congreso Ibero-asiático de Hispanistas Siglo de Oro e Hispanismo general. Delhi, Publicaciones digitales del GRISO/Servicio de Publicaciones de la Universidad de Navarra, 2010, pp.237-265.

GREen, F. J.; Friedman, M. (ed.). Buscando el final del arcoiris. una exploración de las prácticas de crianza desde la fluidez de género. Barcelona, Bellaterra, 2015.

HAlBerstam, J. J. Gaga Feminism: Sex, Gender, and the End of Normal. Boston, Beacon Press, 2012.

HERNÁNDEZ-RODRÍGUEZ, A. Determinación de la filiación de los nacidos en el extranjero mediante gestación por sustitución: chacia una nueva regulación legal en España? Cuadernos de Derecho Transnacional, 6(2), 2014, pp.147-174 [http://erevistas.uc3m.es/index.php/CDT/article/view/2264/1204 - accedido el 28-06-2016]. 
LABACA-ZABALA, M. L. El matrimonio polígamo islámico y su repercusión en el derecho español. Revista Jurídica de Castilla Y León, 2009, pp.261-331.

LEMA TOMÉ, M. Matrimonio poligámico, inmigración islámica y libertad de conciencia en España. Migraciones Internacionales, 2, 2003, pp.149-170.

LeREBOURS-PigeONNIERE, P.; LOUSSOUARN, Y. Droit international privé. Paris, Dalloz, 1962.

LOMBARDO, E. EU Gender Policy: trapped in the Wollstonecraft Dilemma? The European Journal of Women's Studies, 10(2), 2003, pp.159-179.

MARTínEZ, M. M. Límites a la libre circulación de personas en la UE por razones de orden público, seguridad o salud pública en tiempos de crisis: una revaluación a la luz de la jurisprudencia del TJUE. Revista de Derecho Comunitario Europeo, 49, 2014, pp.767-804.

MonREAL, E. N. Defensa de las nacionalizaciones ante tribunales extranjeros. México, Universidad Nacional Autónoma de México, 1976.

Montalvo-ABIOL, J. C. Concepto de orden público en las democracias contemporáneas. Revista Jurídica de La Universidad Autónoma de Madrid, 22, 2010, pp.197-222.

Morelo, P. G. La nueva ley ¿es tan buena como nos la venden? In: Ruiz, M. G. (ed.). Transexualidad. Situación actual y retos de futuro. Asturias, Conseyu de la Mocedá del Principáu d'Asturies, 2007, pp.147-154.

MuÑOZ, E. S. Orden público e impugnación de acuerdos sociales. Revista Xurídica Galega, 54, 2007, pp.13-22.

NoRiEGA, A. E. F. El orden público en el derecho privado. Pontificia Universidad Católica del Perú, 2007 [http://m.tesis.pucp.edu.pe/repositorio/bitstream/handle/123456789/4 680/FERRAND_NORIEGA_ALBERTO_ORDEN_PUBLICO.pdf?sequ ence $=1$ - accedido el 28-06-2016].

ORTEGA, M. Á. Orden público: unidad axiológica, espacio europeo. Anuario de Derecho Europeo, 3, 2003, pp.15-45. 
PICHARDO GALÁN, J. I. (Homo)sexualidad y familia: cambios y continuidades al inicio del tercer milenio. Política Y Sociedad, 46(1), 2009,

pp. $143-60$

[http://revistas.ucm.es/index.php/POSO/article/view/POSO090913014 3A - accedido el 28-06-2016].

; StÉFAnO-BARBERO, M. de; MARTíN-ChiaPPe, M. L. (Des)naturalización y elección: emergencias en la parentalidad y el parentesco de lesbianas, gays, bisexuales y transexuales. Revista de Dialectología Y Tradiciones Populares, 70(1), 2015, pp.187-203.

PIEPER M.; BAUER, R. Call for papers: International conference on polyamory and mono-normativity. University of Hamburg, 5-6 November 2005

[http://www.wiso.unihamburg.de/index.php?id?3495 - accedido el 28-06-2016].

PlATERO MÉNDEZ, R. L. Entre la invisibilidad y la igualdad formal: perspectivas feministas ante la representación del lesbianismo en el matrimonio homosexual. In: SIMONIS, A. (ed.). Cultura, Homosexualidad y Homofobia. Vol II. Amazonia: retos de visibilidad lesbiana. Madrid, Laertes, 2007, pp.85-106.

- Transexualidades. Acompañamiento, factores de salud y recursos educativos. Barcelona, Bellaterra, 2014.

PRECIADO, P. B. Procreación políticamente asistida. Parole de queer, 2014 [http://paroledequeer.blogspot.pt/2014/04/procreacionpoliticamente-asistida-por.html - accedido el 28-06-2016].

SAVIGNY, F. C. Tratado de derecho romano. Vol. VIII. Paris, Institut de France, 1851.

SPADE, D. Una vida normal. Políticas trans críticas y los límites del derecho. Barcelona, Bellaterra, 2015.

SuESS, A. Análisis del panorama discursivo alrededor de la despatologización trans: procesos de transformación de los marcos interpretativos en diferentes campos sociales. In: El género desordenado. Críticas en torno a la patologizacion de la transexualidad. Barcelona y Madrid, Egales, 2010, pp.29-55.

TRUjILlo-BARBADILlO, G. Mi cuerpo es mío: parentalidades y reproducción no heterosexuales. Viento Sur, 146, 2016, pp.61-68. 
VASALLO, B. Limits, boundaries and borders: frontex questioned from a queer non-monogamous perspective. Keynote at 1st International INTIMATE Conference "Queering Partnering", Coimbra, 2015 [http://saladeimprensa.ces.uc.pt/ficheiros/canalces/14097_brigitte_vas allo.mp4 - accedido el 28-06-2016].

WARNER, M. Introduction. Fear of a Queer Planet. Social Text, 29, 1991, pp.3-17.

WitTig, M. El pensamiento heterosexual y otros ensayos. Barcelona y Madrid, Egales, 1992. 